\title{
Animal use in Life Sciences Education: Current Status, Teachers' and Adolescents' Attitudes and Alternatives
}

\author{
Omar Amahmid \\ Regional Centre for Careers of Education and Training, CRMEF- Marrakech, 40000 Morocco, \\ amahmid1969@gmail.com
}

Youssef El Guamri

CRMEF Marrakech, Morocco, research.team.crmef@gmail.com

Mohamed Yazidi

CRMEF Marrakech, Morocco, research.team.crmef@gmail.com

Bouchra Razoki

CRMEF Marrakech, Morocco, research.team.crmef@gmail.com

Khadija Kaid Rassou

CRMEF Marrakech, Morocco, research.team.crmef@gmail.com

Youness Rakibi

CRMEF Marrakech, Morocco, research.team.crmef@gmail.com

Ibrahim Amine Farouk

CRMEF Marrakech, Morocco,svtmar20142015@gmail.com

\section{Fadya Charkaoui}

CRMEF Marrakech, Morocco, svtmar20142015@gmail.com

\begin{abstract}
The study aimed to explore Lower Secondary School curriculum of Life Sciences, in Morocco, to establish the current status of animal use and the extent at which it is a curriculum requirement for the introduction of the prescribed concepts and objectives. Two questionnaires were developed and administered to teachers and students to assess their attitudes towards animal use and dissection, as well as potential alternatives that could be used for replacement. The study revealed that several cited topics in the curriculum involve animal use and organ dissection. The majority of students $(60.9 \%)$ and teachers $(83.3 \%)$ had great interest in performing animal organ dissections, stating that it allowed better understanding, long-term knowledge and motivation. A proportion of participants felt negative emotions towards this practice. Many animals groups have been involved especially frogs and mammals. While most of teachers and students quoted that priority should be given to real hands-on experiments, alternatives preferred for replacement were videos and simulations. Animal use in education raises psychological, ethical, and environmental concerns. Hence, there is a need to use animal-free alternatives as they allow the achievement of the learning objectives more effectively and have several advantages over animal use.
\end{abstract}

Keywords: animal use, dissection alternatives, Life Sciences curriculum, teachers' and students' attitudes

Citation: Amahmid, O., Guamri, Y. E., Yazidi, M., Razoki, B., Rassou, K. K., Rakibi, Y., Farouk, I. A., \& Charkaoui, F. (2019). Animal use in Life Sciences Education: Current Status, Teachers' and Adolescents' Attitudes and Alternatives. Anatolian Journal of Education, 4(2), 69-80. https://doi.org/10.29333/aje.2019.428a 


\section{INTRODUCTION}

The curriculum of Life and Earth Sciences aims to stimulate students' curiosity about nature and to develop scientific thinking, lifelong literacy and skills through observation and hands-on scientific investigations. Moreover, it focused on developing values and attitudes in regard to conservation of natural resources and ethics arising from the conflicting use of the environment... (Curriculum Development Council, 2002; Ministry of National Education [MNE], 2009). As the subject matter of Life Sciences is the living world, the use of animals has been a longstanding tradition and considered as a regular part of the curriculum at Secondary School programs (de Villiers, 2010; Kavai, de Villiers, \& Fraser, 2017). However, during the last decades, this practice has raised much controversy, particularly in developed countries (Capaldo, 2004; Smith \& Smith, 2004; Vollum et al., 2004).

Defenders of animal use assert that hands-on approach is one of most instructive aspects of Life Sciences curriculum and this practice is an absolutely necessary part of an academically rigorous curriculum (Oakley, 2012). They stated that students have the opportunity to see, touch specimens, explore the various organs and how they work, which result in deep comprehension and gaining skills like problem-solving (Garrison, 2007; National Science Teachers Association, 2008). It has been reported that gained knowledge and mastered skills from this hands-on practice has more impact, persist longer, and overly perfect alternatives cannot compete with the learning opportunities that the use of real specimens provide (Allchin, 2005).

On the other hand, animal use as a pedagogical practice has raised ethical and environmental concerns regarding animal welfare standards and potential psychological harm to the student (Bishop \& Nolen, 2001; Hug, 2008). Thus, in many developed countries opponents to animal use including animal welfare activists and animal-rights campaigners debated the logic, rationale and utility of animal dissection in the Life Sciences curriculum (Akbarsha, Zeeshan, \& Meenakumari, 2013; Oakley, 2013). According to these opponents to school curricula should be designed to develop the student's sense of responsibility towards animal welfare, as well as an appreciation of and respect for life. They claimed that a humane education is an education that embodies the values of kindness and compassion in its treatment of animals. Furthermore, animal use in science experiments is a desensitizing experience and may encourage students to abuse animals, and a connection between the way we treat animals and the way we treat fellow humans has been established. For the animal rights defenders, animals have at least the basic right always to be respected as an end in themselves and never to be used merely as a means to an end. Accordingly, animal use in education is an example of human use of animals in which this right is disrespected, and implies using animals as instruments for reaching human purposes. Animals have the rights against pain and distress and hence, their use in such practices is unethical and must be stopped (Rollin, 2003).

The efforts made by these groups of opponents and arguments given have resulted in setting guidelines and regulations for animal dissection and experimentation. The "Three Rs" (replacement, reduction and refinement) guideline has been reported as the most applied in educational contexts resulting in a decrease or phasing out animal classroom-based dissections in secondary schools in many countries (Buchanan-Smith et al., 2005; Kilkenny, Browne, Cuthill, Emerson, \& Altman, 2010; Malone, Tuman-Rugg, Perlman, \& Capitano, 2011; Richmond, 2010). In addition, the choice policy that gives students the right to opt out of dissection and use an alternative instead, and resolutions that encourage teachers to provide alternatives to dissection have been implemented in several countries (Duncan, 2008; Kramer, 2007; Oakley, 2012, 2013). These policies have been supported by the numerous dissection alternatives available including virtual dissections, anatomical models, films, on-line presentations, plastinated specimens... (Jukes \& Chiuia, 2003; Smith \& Smith, 2004). Due to potential and advantages of animal-free alternatives use in education and teaching, the animal welfare/rights activists have seriously pondered the lack of relevance of involving animals in such practices.

Anatolian Journal of Education, October $2019 \bullet$ Vol.4, No.2 
However, in the developing countries, such debate is new to the public domain and do not seem a priority (Akbarsha et al., 2013; de Villiers, 2010). It has been reported that while animal-related laws currently occur in most countries, they appear to lack any specific reference to classroom uses of animal. Only a few countries have enacted laws affecting animal use in education (Balcombe, 2000). Studies carried out on the status and implications of animal use in education in developing countries are rare (de Villiers \& Sommerville, 2005; Kavai et al., 2017; Kimwele, Matheka, \& Ferdowsian, 2011). In Morocco, where wild animals protection law exists, there appears to be no official reporting or regulations regarding animal use in education. In 2010 participants from 24 countries, including Morocco, attended the First North Africa and Middle East Seminar on Alternatives to Animal Experiments in Education and Training, held in Egypt. The resolution passed at the seminar recognized the pedagogical, ethical, environmental and economic advantages of humane alternatives over harmful animal use in education and training. It called on governments and educational institutions to work towards removing harmful animal use from the life science syllabus, to develop appropriate regulations and guidelines to bring about replacement, and to provide support for the implementation of alternatives (Elzaabalawy et al., 2011).

The current study aimed to explore the Moroccan curriculum of Life and Earth Sciences designed for the lower secondary school level, in order to assess the extent to which the curriculum implementation involved animal use and organs dissection to introduce concepts and develop students' skills. The second objective of the study was to investigate the teachers and students experiences and attitudes towards animal use and organ dissection, and their potential alternatives for replacement.

\section{METHOD}

\section{Study Design and Approach}

Education in Morocco is provided mainly by the Moroccan government through the Ministry of National Education. Basic education is divided into six years (grades 1-6) of Primary School Education, generally attended by 6-12 years aged children; and 3 years (grades 1-3) of Lower Secondary School Education level (Sassi, Bouderga, Chaibi, \& Hammani, 2015). The study was designed for lower secondary school level. This level is one of the most critical education stages where growing teens develop significant ability to assess and comprehend complex situations and information, learn material that will shape their thinking process with an increasing need for autonomy (Story \& Stang, 2005). Moreover, with respect to the development related to the surrounding environment, adolescents gain an awareness of human intervention in the natural environment. Adolescents can also develop a sense of moralism as they can make more informed value judgments based on a valid working knowledge of basic ecological concepts (Rejeski, 1982).

The first phase of the study started as a content (textual) analysis through which the researchers analyzed the national compulsory curriculum and syllabus of Life and Earth Sciences designed for the Lower Secondary School level. The content is delivered using competency-based and values-driven approaches (MNE, 2009). The criteria for this analysis were based on experiments and demonstrations involving animal use or organ dissection for the implementation of the prescribed curriculum of Life Sciences (Kavai et al., 2017).

The second phase consisted of an exploratory study where teachers and learners, in lower secondary schools in Marrakesh, completed a questionnaire to investigate their experience and attitudes as well as alternatives with regards to animal use in Life Sciences Education.

\section{Participants}

The present study investigated two groups of participants consisting of students and teachers. The students group included 92 adolescents, from both genders (38 boys and 54 girls) aged between 12 
and 15 years. The inclusion criteria were: students attending lower secondary school having science lab, and studying all the topics of the National Curriculum of Life and Earth Sciences designed for this level. The schools were located in districts with medium living standards. All the students who consented to participate in the study have been included. Participation was fully voluntary and informed consent was taken from the Heads of the schools and participants.

For the teachers' group, a total of 30 teachers ( 20 male and 10 female) participated in the study. Their teaching experience ranged from one to more than 20 years. The inclusion condition was: teaching Life Sciences in secondary school level according to the prescribed National Curriculum. All the teachers who accepted to be a part of the survey have been included. Consent was sought from the participants.

\section{Data Collection Tools}

Self-administered questionnaires have been reported as suitable instruments to assess attitudes in learning and teaching environment (de Villiers \& Sommerville, 2005; Knight, Vrij, Cherryman, \& Nunkoosing, 2010; Radhakrishna, 2007; Seker, 2017). Offering anonymity on self-administered questionnaires should further reduce social pressure, and thus may likewise reduce social desirability bias (Taylor-Powell, 2006). They are considered as effective means of measuring the behavior, attitudes, preferences, opinions and, intentions of relatively large numbers of subjects more cheaply and quickly than other methods (Mathers et al., 2007). On the basis of the analysis of the National Curriculum of Life Sciences and the literature linking to animal use in education, and according to the study assessment goals, two questionnaires have been developed. In addition to demographic details, the questionnaires' items consisted of multiple-choice questions and short-answer questions, specifically focused on the respondents' experience, attitudes, opinions, preferences, and feelings towards animal use and organ dissection in Life Sciences. The participants were informed about the goals of the research, given specific instructions about filling the questionnaire fields, and guaranteed anonymity. Additionally, they were informed that answering was on a free will basis. There was no time limit for completion of the questionnaires.

\section{Methods of Data Analysis}

The survey data were analyzed using descriptive statistical analysis techniques (calculating percentages and counting frequencies) (Loeb et al., 2017). The Chi-square test was applied to determine the statistical significance of differences. All data were analyzed using Excel and Social Statistics pack for Social Sciences (SPSS 17) software (Chicago, IL, USA) with a p-value <0.05 was considered as statistically significant.

\section{FINDINGS}

\section{Animal use and Organ Dissection for the Curriculum Implementation}

The first part of the present study consisted of analyzing the content of Moroccan curriculum designed for Life Sciences education in lower secondary school level. It aimed to identify the demonstrations and experiments involving animal use or organ dissection that can be used for the introduction of the curriculum content (Table 1). The exploration of the curriculum revealed that the experimental approach is privileged in teaching Life Sciences and solving problems. Students were to observe, hypothesize; collect and record data; organize and interpret findings; and formulate conclusions and generalizations (MNE, 2009). The study revealed that during the curriculum process several experiments using animals or organ dissection are required in all grades to introduce and grasp the concepts prescribed and ensure student achievement (Table 1). The most concerned was grade 3 with several covered topics, offering opportunities of animal usage or organ dissection, including the nervous, muscular, circulatory and excretory systems. In grade 1, cited topics included the exploration 
of a natural environment, animal respiration in different mediums, then humans and vertebrate's nutrition. For grade 2 the main involved topic was sexual reproduction in animals. Many categories of animals can be used to achieve the demonstrations and experiments including Molluscs, Insects and other Invertebrates, Amphibians, Mammals...

Table 1

Demonstrations, Observations and Experiments Involving Animal use or Organ Dissection in Life Sciences Education in the Lower Secondary School Curriculum (MNE, 2009)

\begin{tabular}{|c|c|c|}
\hline Grades & Topics & Experiments \\
\hline \multirow{3}{*}{1} & $\begin{array}{l}\text { Exploration of a } \\
\text { natural environment }\end{array}$ & Extraction of invertebrates from soil samples using Berlese funnel \\
\hline & $\begin{array}{l}\text { Animal respiration in } \\
\text { different mediums }\end{array}$ & $\begin{array}{l}\text { Respiratory System - Respiration system in Insects, fish, and terrestrial } \\
\text { vertebrates. }\end{array}$ \\
\hline & $\begin{array}{l}\text { Humans and } \\
\text { vertebrate's nutrition }\end{array}$ & $\begin{array}{l}\text { Dissection of an herbivore animal (rabbit) to explore the anatomy of the } \\
\text { digestive tract }\end{array}$ \\
\hline \multirow[t]{2}{*}{2} & \multirow{2}{*}{$\begin{array}{l}\text { Sexual reproduction } \\
\text { in animals }\end{array}$} & $\begin{array}{l}\text { Dissection of a mammal (mouse) to explore and identify the } \\
\text { reproductive system }\end{array}$ \\
\hline & & Extraction and observation of fish gametes \\
\hline \multirow{8}{*}{3} & $\begin{array}{l}\text { The circulatory } \\
\text { system }\end{array}$ & $\begin{array}{l}\text { Dissection and observation of sheep heart to identify and explore the } \\
\text { external and internal structures }\end{array}$ \\
\hline & The excretory system & $\begin{array}{l}\text { Dissection and observation of sheep kidney to explore the external and } \\
\text { internal structures. }\end{array}$ \\
\hline & \multirow{4}{*}{ The nervous system } & $\begin{array}{l}\text { Dissection and observation of cow's eye to explore the external and internal } \\
\text { structures }\end{array}$ \\
\hline & & $\begin{array}{l}\text { Dissection and observation of the sheep's brain to identify the main } \\
\text { structures and major parts }\end{array}$ \\
\hline & & Frog spinal reflex \\
\hline & & Observation of the spinal cord \\
\hline & \multirow{2}{*}{ The muscular system } & Exploration of the skeletal muscle characteristics/properties in frog muscle \\
\hline & & Observation of the skeletal muscle structure \\
\hline
\end{tabular}

\section{Survey Results}

The survey aimed to explore the teachers and students current experience as well as their attitudes towards animal use and organ dissection in Life Sciences. The study findings, as seen in Table 2, showed that the majority of teachers $(83.3 \%)$ and students $(60.9 \%)$ were in favour of animal use in school experiments and demonstrations, with a statistically significant difference between groups and proportions $(\mathrm{p}<0.05)$. For both groups, the main justifications (in order) were better understanding of science concepts, long-term knowledge and motivation. However, $16.7 \%$ of teachers and $39.1 \%$ of students have stated to disagree with animal dissection in school education, mainly because of being cruel to animals (Table 2).

Of the investigated teachers $86.7 \%$ stated that they have conducted experiments and/or dissection on animal organs, while $13.3 \%$ did not. The latter considered the lack of time and/or unavailability of apparatus as the main reasons for skipping this practice. For students, $65.2 \%$ declared to have attended to such experiments in class; however, in $83.3 \%$ of cases it consisted of demonstrations by the teacher, versus $13.7 \%$ done by the students themselves.

Just over $80 \%$ of the teachers and $60 \%$ of the students felt comfortable with carrying out animal organ dissection themselves, while $21.7 \%$ and $6.7 \%$ were not comfortable with the same idea, respectively; and the observed differences were statistically significant $(\mathrm{p}<0.01)$. A proportion of teachers $(3.3 \%)$ as well as students $(8.7 \%)$ stated that they feel feared when carrying out dissection. Many species or 
groups of animals were used for Life Sciences education (Figure 1). Based on the study findings frogs were the most common species used, with fishes, rats, rabbits, and cows and sheep (used for their $\mathrm{s}$ organs, e.g. eyeball, heart, kidney, lungs...) also predominating. Invertebrates such as Insects and Molluscs (snails and bivalves) have been used for observation or dissection purposes. The main route of obtaining animals was through collecting specimens from the wild or buying in Market, or butcher shops for organs.

Table 2

Teachers' and Students' Attitudes and Practice towards Animal use and Dissection in Life Sciences Education

\begin{tabular}{lll}
\hline Items & Teachers (\%) & Students (\%) \\
\hline Have you used animal in class & & \\
- Yes & 86.7 & $65.2 *$ \\
- No & 13.3 & 34.8 \\
- In favor of animal use in Life Sciences? & 83.3 & 60.9 \\
$\quad \quad$ Proportions & & \\
- Justifications & 56.7 & 34.5 \\
- Deep understanding and assimilation & 16.7 & 19.7 \\
- Memorize/long-term knowledge & 10.0 & 6.7 \\
- Motivation & 16.7 & 39.1 \\
- Against/disagreement animal use & & \\
- Proportions & 10.0 & 38 \\
- Justifications & 6.7 & 1.1 \\
- suffering of animals & & 60.9 \\
- Personal feelings & 86.7 & 21.7 \\
- Attitudes when experimenting on animals & 6.7 & 8.7 \\
- Comfortable & 3.3 & 8.7 \\
- Stressed/uncomfortable & 3.3 & \\
- Scared & Other &
\end{tabular}

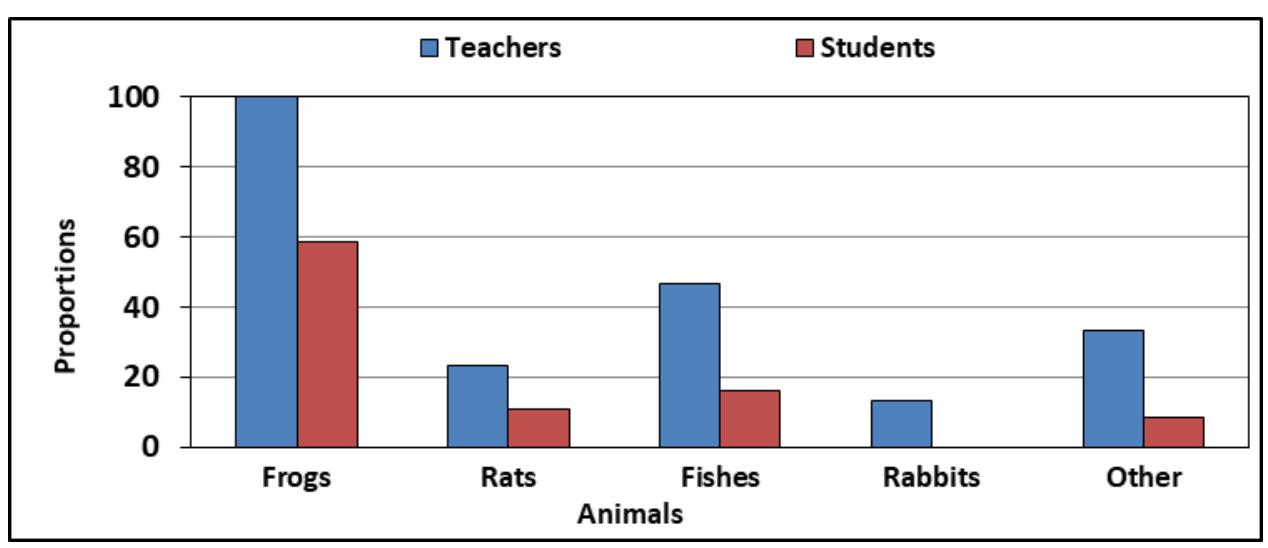

Figure 1

Species or Groups of Animals used in Life Sciences Teaching

With regards to the participants' preferences, most of the investigated teachers $(73.3 \%)$ and students $(54.4 \%)$ stated that priority should be given at first to real hands-on experiments, and virtual alternatives such as videos and computer simulations can be used as substitutes (Figure 2). 




Figure 2

Teachers and Students Preferences and Alternatives for Animal use

\section{DISCUSSION}

The use of animals in Life Sciences education has been common for decades in many countries worldwide. This practice has long been the subject of heated debate due to its psychological, moral, ethical and environmental implications. Several studies have been focused on the status and implications of animal use in school education in developed countries. Yet in developing countries, including Morocco, little attention has been accorded to this issue, not considered as a priority.

As the educational curricula and programs are critical tools that teachers rely on to teach and train their students, the animal use in education is generally considered a curriculum requirement. In Morocco, the curriculum of Life and Earth sciences draws upon the tenets of the competency as well as the innovative active learning-oriented pedagogical model. It is mainly designed to build upon interest in and stimulate curiosity about the environment, gain deeper personal insights and gain aesthetic appreciation of the natural world (Sassi et al., 2015). The study findings revealed that the introduction of Life and Earth Sciences curriculum in the Lower secondary school level involves animal usage and organ dissection in many topics. The third-grade syllabus included relatively more topics involving animal use to introduce the concepts, as compared to grade 1 and grade 2 . Consequently, dissections opportunities are more common amongst grade 3, with fewer in the other grades. The animals were predominantly used for teaching the structure and function of the body at all year levels, but specific body systems (e.g. digestive, reproductive, nervous...) were cited as topics of dissection. These findings indicate that Life Sciences allow considerable scope for the use of live animals and other living organisms. This require sessions that include dissections of animal organs in order to introduce concepts and develop the targeted skills including investigation, inquiry and problem-solving skills. The study results concur with reports from other countries indicating that animal use and dissection during the school curricula implementation appeared a widespread practice in many countries in different continents (Balcombe, 2000; King, Ross, Stephens, \& Rowan, 2004; Oakley, 2012; Spernjak \& Sorgo, 2017). Conversely, in other countries the hands-on dissection has been restricted or dropped from the curriculum (Balcombe, 2001; Mattheis, Ingram, Jensen, \& Jackson, 2015).

The investigation of teachers' and students' attitudes revealed that the majority $(83.3 \%$ of teachers and $60.9 \%$ of students) was in favor of animal use and dissection in Life Sciences education. The main reasons were deeper understanding, long-term knowledge and motivation. Generally, teachers showing more positive inclination towards dissection believe that careful performance of dissection has the potential for increasing student understanding of the organism, encouraging a greater appreciation of 
human anatomy, and developing higher-level thinking skills (Oakley 2012). The inclination of teachers towards animal may also be explained by the fact that it is part of the national compulsory curriculum and supported by the Ministry of Education. The study findings corroborated those previously reported by other authors who found that most of the investigated teachers were in favour of animal dissection, and believe that more dissection work should be done in school Life Sciences than was then the case (de Villiers \& Sommerville, 2005; Institute of Biology, 2007).

With respect to students' attitudes, animal use was considered as source of motivation allowing better understanding and long-term knowledge. This is in accordance with the findings of previous reports indicating that most of students enjoyed using animals and organ dissection (Kavai et al., 2017; (Lombardi, Hicks, Thompson, \& Marbach-Ad, 2014; Spernjak \& Sorgo, 2017). Conversely, a considerable proportion of respondents reaching $39.1 \%$ of the investigated students and $16.7 \%$ of teachers had negative inclination towards animal dissection, mainly because of animal suffering. This may reflect reflect that students began to develop positive attitudes and beliefs towards animals. These attitudes may be influenced by several factors such as sex, age, experience to belief in animal cognition and sentience, religion and effect of social media. The finding is in accordance with studies reporting negative inclinations among students, claiming that students disapproved of the killing of animals for educational purposes (Birdsall \& France, 2011; Donaldson \& Downie, 2007). The study revealed that $86.7 \%$ of the investigated teachers have used animals in Life Sciences education while $13.3 \%$ did not. The main reasons skipping this practice were the lack of time, shortage of effective instructional materials and/or animals not available, and no personal reasons have been given. Yet the extent to which teachers become engaged with animal-related dissections may be influenced by several other factors. These include culture, feeling of proficiency, emotional status, specific lifetime experiences with animals and duty to fulfill the curriculum requirements (Holstermann, Grube, \& Bogeholz, 2009).

Among the investigated students $65.2 \%$ stated that they have attended animal organ dissection but in $83.3 \%$ of cases it was done by the teacher. Interestingly, while dissections performed as teacher demonstrations have potential to achieve several curriculum objectives it may also result in a reduction in the numbers of animals used. In addition, everyday practice demonstrations may be relevant because of high costs of hands-on dissection (Havlickova, Sorgo, \& Bilek, 2018).

Significantly higher proportions of the teachers $(86.7 \%)$ and students $(60.9 \%)$ stated they felt comfortable with carrying out themselves animal organ dissection, or watching the teacher or classmate performing this practice. However, $21.7 \%$ of students versus $6.7 \%$ of teachers declared they were not comfortable with such activity. While teachers have been commonly found to be comfortable with dissection, students were reported to be relatively more affected, regardless of their nationality. The expressed inclination may range from been emotionally affected to being disgusted (Kavai et al., 2017; Osenkowski, Green, Tjaden, \& Cunniff, 2015; Spernjak \& Sorgo, 2017). This issue raises the psychological implications of animal experiments. Indeed, animal use and dissection in Life Sciences education may engender negative emotions such as fear, anger, sadness and disgust among students. These can negatively impact on students' self-efficacy belief and reduce their interest levels and cognitive abilities, resulting in less learning. Students may become desensitized and develop a utilitarian view of animals, thereby diminishing their capacity for compassion and ethical decisionmaking (Holstermann et al., 2009).

The study findings showed that a wide range of animals (invertebrates and vertebrates) can be used for observation, dissection or as sources of dissected organs in Life Sciences education. They were predominantly used for teaching the structure and function of specific body systems. However, several other topics including behavior, taxonomy may involve animal use. The type and number of animals involved may vary depending on the students' number, grades and syllabus topics requiring animal 
use. Large ranges of animal species have been found to be commonly dissected raising the environmental implications of this practice (Balcombe, 2000; Birdsall \& France 2011).

In relation to teachers' and students' preferences and alternatives, the majority of the investigated teachers and students favored real hands-on experiments. However, considerable proportions of both groups (45.6\% of students and $26.7 \%$ of teachers) expressed that virtual alternatives such as videos and simulations may be used as substitutes. The teachers and students being pros to hands-on practice may not be aware of the availability of alternatives to animal use allowing equivalent outcomes. Moreover, the lack of training and not understanding the way to use such alternatives may explain their attitude.

Teachers' and students' point of view and attitudes to animal use alternatives were found to be sparse. Surveys revealed that although teachers have stated using alternative resources, only a third of them agreed that these were as good as dissection for teaching anatomy and/or physiology, and many teachers offered both dissection and alternatives (Almy, Goldsmith, \& Patronek, 2001; King et al., 2004). In contrast, many reports indicated that science teachers valued positively both hands-on and virtual variants of dissection, reporting that both variants outcomes were equivalent (Akbarsha et al., 2013; Havlickova et al., 2018; Lalley, Piotrowski, Battaglia, Brophy, \& Chugh, 2010). More students than teachers had positive inclination to non-animal alternatives, suggesting an increasing tendency to exchange animal use with alternatives among students (Osenkowski et al., 2015). In this context, it has been proposed that public opinions and associated teachers' and students' attitudes to a substitute of hands-on dissection will slowly change resulting in a gradual reduction of frequency of hands-on dissection and replacement with various kinds of dissection alternatives.

\section{CONCLUSION}

Based on the study findings it has been found that the introduction of the Moroccan curriculum of Life Sciences in the Lower secondary school level involved animal usage and organ dissection in many topics including structure and function of the body. Thus, animal use and dissection is a curriculum requirement to introduce concepts and develop skills described in Life Sciences syllabus.

The current study results showed that the inclinations of adolescents and teachers towards animal use were predominantly positive. The main considerations were motivation, skills development, deeper understanding and long-term knowledge. Approximately a third of students and teachers expressed negative inclination towards this practice essentially because of animal suffering. This may be considered as an emerging sense of awareness and consciousness regarding the cruelty of animal dissection. Such attitude may be related to several influencing factors including experience of animals, beliefs in animal cognition and sentience. These factors may result in a development of sense of empathy and compassion to animals with belief in animal welfare and rights. A proportion of students reported feeling negative emotions towards animal dissection. These negative emotions may weaken students' interest in Life Sciences, and influence negatively on their cognitive performance and learning achievement. Moreover, a wide range of animals were used during the implementation of the Life Sciences curriculum. So environmental implications of animal use should be acknowledged and taken into account as another factor in addition to ethical and emotional reasons.

For the students' and teachers' preferences and potential alternatives to animal organ dissection and usage, hands-on experiments were the most favored. However considerable proportions of both groups stated that virtual alternatives such as videos and computer simulations can be used as a replacement. The psychological consequences to students combined with social, environmental, educational and ethical considerations can present a compelling argument for total replacement of the harmful use of animals in education. At present there are a wide range of animal-free models available for use in Life Sciences education offering several advantages equivalent or over animal experiments. Consequently, 
guidelines for the use of animals in teaching should be established and implemented. Learning objectives should be redefined and syllabi should be framed in such a manner that guidelines do not contradict the curriculum. Appropriate alternatives should be provided to schools and everyone involved in education and training, and especially lecturers and students, should have access to comprehensive information about alternatives. Ideally, this information should not only contain descriptions of the available alternatives, but also evidence of their educational benefits.

\section{ACKNOWLEGEMENTS}

The authors would like to thank all participants in this study for their valuable cooperation.

Funding

No funding sources.

Declaration of Interest Statement

None declared.

\section{REFERENCES}

Akbarsha, M. A., Zeeshan, M., \& Meenakumari, K. J. (2013). Alternatives to animals in education, research, and risk assessment: An overview with special reference to Indian context. Proceedings of Animal Alternatives in Teaching, Toxicity Testing and Medicine. Altex 2(1), 5-13.

Allchin, D. (2005). Hands-off dissection? What do we seek in alternatives to examining real organisms? The American Biology Teacher, 67(6), 369-374.

Almy, J., Goldsmith, M., \& Patronek, G. (2001). Dissection in Massachusetts classrooms: Correlation of gender, teacher attitudes, and conscientious objection. (Report). West Barnstable, MA: Cape Wildlife Center.

Balcombe, J. P. (2000). A global overview of law and policy concerning animal use in education. In M. Balls, A. M. Zeller, \& M. E. Halder (Eds.), Progress in the reduction, refinement and replacement of animal experimentation (pp. 1343-1350). New York: Elsevier.

Balcombe, J. P. (2001). Dissection: The scientific case for alternatives. Journal of Applied Animal Welfare Science, 4(2), 118-126.

Birdsall, S., \& France, B. (2011). Attitudes towards using animals in research and teaching: Opinions from a selected group of female secondary school students. Kotuitui. New Zealand Journal of Social Sciences Online, 6(1-2), 15-25.

Bishop, L. J., \& Nolen, A.L. (2001). Animals in research and education: Ethical issues. Kennedy Institute of Ethics Journal, 11(1), 91-112.

Buchanan-Smith, H. M., Rennie, A. E., Vitale, A., Pollo, S., Prescott, M. J., \& Morton, D. B. (2005). Harmonizing the definition of refinement. Animal Welfare, 14(4), 379-384.

Capaldo, T. (2004). The psychological effects on students of using animals in ways that they see as ethically, morally or religiously wrong. Alternatives to Laboratory Animals, 32(Suppl 1b), 525-531.

Curriculum Development Council (2002). Key learning area curriculum guide. Science Education (Primary 1-Secondary 3). Hong Kong.

de Villiers, R. (2010, January). The use of animals in education and research: do animals have rights? In V. Mudaly (Ed.), Proceedings of the Eighteenth Annual Meeting of the Southern African Association for Mathematics, Science and Technology - Crossing the boundaries (pp. 170-177). Kwazulu Natal.

de Villiers, J. J. R., \& Sommerville, J. (2005). Prospective biology teachers' attitudes toward animal dissection: Implications and recommendations for the teaching of biology. South African Journal of Education, 25(4), 247-252. 
Donaldson, L., \& Downie, R. (2007). Attitudes to the uses of animals in higher education: Has anything changed? Bioscience Education, 10(1), 1-13.

Duncan, A. (2008). To dissect or not: Student Choice-in-dissection laws ensure the freedom to choose. Journal of Law and Education, 37(2), 283-289.

Elzaabalawy, S. I., Abdelbaki, M. A., Abdelhakim, A. I., Alamir, W. A., Elsayed M. O., Erian, M. M. ..., Shaheen, M. A. (2011, August). Alternatives outreach and a new student movement for humane veterinary education and practice in Egypt. Altex Proceedings, Proceedings of WC8, The Three Rs Together It's Possible 1(1), 387-393.

Garrison, D. R. (2007). Online community of inquiry review: Social, cognitive, and teaching presence issues. Journal of Asynchronous Learning Networks, 11(1), 61-72.

Havlickova, V., Sorgo, A., \& Bilek, M. (2018). Can virtual dissection replace traditional hands-on dissection in school biology laboratory work? EURASIA Journal of Mathematics, Science and Technology Education, 14(4), 1415-1429.

Holstermann, N., Grube, D., \& Bogeholz, S. (2009). The influence of emotion on students' performance in dissection exercises. Journal of Biological Education, 43(4), 164-168.

Hug, B. (2008). Re-examining the practice of dissection: What does it teach? Journal of Curriculum Studies, 40(1), 91-105.

Institute of Biology. (2007). Are fewer dissections being done in school science lessons? Executive Summary. London.

Jukes, N., \& Chiuia, M. (2003). From Guinea pig to computer mouse: Alternative methods for a progressive, humane education. Leicester: InterNICHE.

Kavai, P., de Villiers, R., \& Fraser, W. (2017). Teachers' and learners' inclinations towards animal organ dissection and its use in problem-solving. International Journal of Instruction, 10(2), 39-54.

Kimwele, C., Matheka, D., \& Ferdowsian H. (2011). A Kenyan perspective on the use of animals in science education and scientific research in Africa and prospects for improvement. Pan African Medical Journal, 9(45), 1-6.

Kilkenny, C., Browne, W. J., Cuthill, I. C., Emerson, M., \& Altman, D. G. (2010). Improving bioscience research reporting: The ARRIVE guidelines for reporting animal research. PLoS Biology, 8(6), e1000412.

King, L. A., Ross, C. L Stephens, M. L., \& Rowan, A. N. (2004). Biology teachers' attitudes to dissection and alternatives. Alternatives to Laboratory Animals, 32(S1), 475-484.

Knight, S., Vrij, A., Cherryman, J., \& Nunkoosing, K. (2004). Attitudes towards animal use and belief in animal mind. Anthrozoos, 17(1), 43-62.

Kramer, M. G. (2007). Humane education, dissection, and the law. Animal Law, 13(281), 281-298.

Lalley, J. P., Piotrowski, P. S., Battaglia, B., Brophy, K. \& Chugh, K. (2010). A comparison of VFrog to physical frog dissection. Int. J. of Environmental and Science Education, 5, 189-200.

Loeb, S., Dynarski, S., McFarland, D., Morris, P., Reardon, S., \& Reber, S. (2017). Descriptive analysis in education: A Guide for Researchers. NCEE 2017-4023. Washington, DC.

Lombardi, S. A., Hicks, R. E., Thompson, K. V., \& Marbach-Ad. G. (2014). Are all hands-on activities equally effective? Effect of using plastic models, organ dissections, and virtual dissections on student learning and perceptions. Advances in Physiology Education, 38(1), 80-86. 
Malone, B., Tuman-Rugg, C., Perlman, L., \& Capitano, E. (2011). Use of animals in the school classroom. The school district of Palm Beach County. Department of Secondary Curriculum, West Palm Beach, Florida.

Mattheis, A., Ingram, D., Jensen, M. S., \& Jackson, J. (2015). Examining high school anatomy and physiology teacher experience in a cadaver dissection laboratory and impacts on practice. International Journal of Science and Mathematics Education, 13(3), 535-559.

Mathers, N, Fox, N., \& Hunn, A. (2007). Surveys and questionnaires. The NIHR RDS for the East Midlands / Yorkshire \& the Humber.

Ministry of National Education (MNE) (2009). Lower Secondary School pedagogical guidelines. Life and Earth Sciences. Directorate of Curricula, Rabat, Morocco.

National Science Teachers Association, (2008). Position statement on responsible use of live animals and dissection in the science classroom. NSTA. Retrieved from http://www.nsta.org/docs/PositionStatement_LiveAnimalsAndDissection.pdf.

Oakley, J. (2012). Science teachers and the dissection debate: Perspectives on animal dissection and alternatives. International Journal of Environmental and Science Education, 7(2), 253-267.

Oakley, J. (2013). I didn't feel right About animal dissection: Dissection objectors share their science class experiences. Society and Animals, 21(4), 360-378.

Osenkowski, P., Green, C., Tjaden, A., \& Cunniff, P. (2015). Evaluation of educator and student use of and attitudes toward dissection and dissection alternatives. The Am. Bio. Teac., 77(5), 340-346.

Radhakrishna, R.B. (2007). Tips for developing and testing questionnaires/instruments. Journal of Extension, 45(1), 1-4.

Rejeski, D. W. (1982). Children look at nature: Environmental perception and education. Journal of Environmental Education, 13(4), 27-40.

Richmond, J. (2010). The three Rs. In R. Hubrecht, \& J. Kirkwood (Eds.), UFAW handbook on the care and management of laboratory and other research animals (pp. 5-22). Oxford, U.K: John Wiley \& Sons.

Rollin, R.E. (2003). Toxicology and new social ethics for animals. Toxic. Pathology, 31(S), 128-131.

Sassi, M., Bouderga, S., Chaibi, A. \& Hammani, M. (2015). The Kingdom of Morocco. TIMSS Encyclopedia, TIMSS and PIRLS, International Study Center, Lynch School of Education, Boston College.

Seker, H. (2011). Developing a questionnaire on attitude towards school. Learning Environments Research, 14(3), 241-261.

Smith, A. J., \& Smith, K. (2004). Guidelines for humane education: Alternatives to the use of animals in teaching and training. Alternatives to Laboratory Animals, 32(S1-A), 29-39.

Spernjak, A., \& Sorgo, A. (2017). Dissection of Mammalian organs and opinions about it among Lower and Upper Secondary School students. CEPS Journal, 7(1), 111-130.

Story, M. \& Stang, J. (2005). Nutrition needs of adolescents. In J. Stang, M. Story (Eds.), Guidelines for adolescent nutrition services (pp. 21-34). University of Minnesota, Minneapolis.

Taylor-Powell, E. (2006). Questionnaire Design. Wisconsin: Cooperative Extension Service, University of Wisconsin-Extension.

Vollum, S., Buffington-Vollum, J., \& Longmire, D. R. (2004). Moral disengagement and attitudes about violence towards animals. Society and Animal, 12(3), 208-235. 